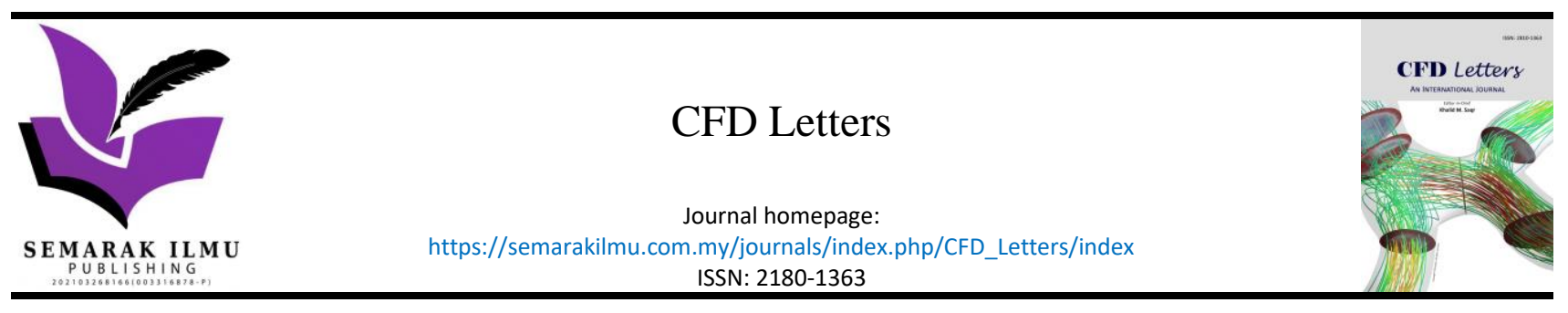

\title{
Laminar Separation Bubble and Flow Topology of NACA 0015 at Low Reynolds Number
}

\author{
Mohamed Ibren ${ }^{1}$, Amelda Dianne Andan ${ }^{1,}{ }^{*}$, Waqar Asrar ${ }^{1}$, Erwin Sulaeman ${ }^{1}$ \\ Department of Mechanical Engineering, Kulliyyah of Engineering, International Islamic University Malaysia, Kuala Lumpur, 53100, Malaysia
}

\section{ARTICLE INFO}

\section{Article history:}

Received 14 August 2021

Received in revised form 16 September 2021

Accepted 17 September 2021

Available online 31 October 2021

\section{Keywords:}

Low-Reynolds Number; SST $\gamma-R e_{\theta^{-}}$ model; Transition simulation; Laminar separation bubble; NACA 0015 airfoil

\section{ABSTRACT}

The development of sophisticated unmanned aerial vehicles and wind turbines for daily activities has triggered the interest of researchers. However, understanding the flow phenomena is a strenuous task due to the complexity of the flow field. The engaging topic calls for more research at low Reynolds numbers. The computational investigations on a two-dimensional (2D) airfoil are presented in this paper. Numerical simulation of unsteady, laminar-turbulent flow around NACA 0015 airfoil was performed by using shear-stress transport (SST) model at relatively low Reynolds number $\left(8.4 \times 10^{4}\right.$ to $\left.1.7 \times 10^{5}\right)$ and moderate angles of attack $(0 \leq \alpha \leq 6)$. In general, on the suction side, with increasing Reynolds number and angles of attack, separation, and reattachment point shifts upstream and concurrently shrinking the size of the laminar bubble. However, On the pressure side, the laminar bubble is seen to move toward the trailing edge at the relatively same size as the angle of attack increases. Moreover, the variations in the angle of attack have more influence on the laminar separation bubble characteristics as compared to the Reynolds number. The reattachment points were barely observed for the range of the angles of attack studied. At very high angles of attack, it is recommended to simulate the flow field using large eddy simulation or direct numerical simulation since the flow is considered three-dimensional and detached from the surface thus forming a complex phenomenon.

\section{Introduction}

The study on low Reynolds numbers $\left(R e<10^{6}\right.$ ) has shown tremendous improvement due to technological advancement [1]. For Instance, the development of sophisticated unmanned aerial vehicles used in daily activities has triggered the interest of the researchers. However, due to the complexity of the flow field, it has become strenuous to understand the flow phenomenon [1,2]. In addition, computer simulation is one of the methods used to understand the physics of the flow structure over the airfoils since it is cost-efficient. Computer simulation enables better visualization of the flow topology. Hence, optimal optimization can be achieved easily.

At a relatively low Reynolds number, the laminar boundary layer (LBL) often separates on the suction surface due to a strong adverse pressure gradient, which leads to the formation of a

* Corresponding author.

E-mail address: ameldadianne@iium.edu.my (Amelda Dianne Andan) 
separated shear layer [3-6]. Similarly, the flow will remain separated thus, forming a large wake if the adverse pressure gradient is large and paired with weak momentum [7]. Moreover, a separated shear layer allows rapid growth of the vortices due to its instability to the disturbances [8]. The vortices are crucial in developing the flow and affect the formation of separation bubbles [1]. Upstream disturbances before the separation point act as the initial instabilities [1]. Consequently, the flow behavior will be affected and thus should be considered when analyzing the flow mechanism.

Furthermore, the separated flow may trip the boundary layer (BL) thus, developing hydrodynamic instabilities in the shear layer. These instabilities tend to break down nonuniformly into a chaotic flow $[8,9]$. The flow characteristic is associated with changes in fluid pressure and flow velocity.

Alternatively, the flow underdoes rapid transition to turbulence [6,9]. The turbulent flow may reattach behind a vortical structure known as the 'reverse-flow vortex' due to increased momentum of the flow forming the turbulent boundary layer (TBL) $[3,6]$. The intensified shear layer reattaches to the surface resulting in a bounded recirculation region known as a laminar separation bubble (LSB) $[3,6,9]$. Downstream the laminar separation bubble, the turbulent flow might separate again or reattach towards the trailing edge [7].

Laminar separation bubbles are frequently observed at relatively low Reynolds number regimes. The bubbles are classified into two types, namely short and long bubbles. The short bubbles were observed to have the length of $0.1 \mathrm{C}$ and $102 \delta_{s}^{*}$ to $103 \delta_{s}^{*}$, where $\delta_{s}^{*}$ and $\mathrm{C}$ are the displacement thickness at separation point and chord length, respectively. The long bubbles have the length of order $104 \delta_{s}^{*}[10]$.

Moreover, the short bubbles often affect the external potential flow, whereas the long bubbles altered the pressure distribution over an object [6]. A slight change in the Reynolds number (Re) and/or angle of attack (AoA) may create, break out, or vanish laminar separation bubble [11]. In addition, short bubbles burst to form large bubbles with reattachment far downstream or without reattachment at moderate incidence. At incidence below stall, bubble controls the transition process, whereas bursting bubble determines the stalling of the model $[6,8]$. Furthermore, the nature of the bubble, such as bursting, affects the aerodynamic performance. Bubbles may increase lift, intensifies unsteadiness, and reduces the drag coefficient $[8,12,13]$. Likewise, Reynolds number, angle of attack, airfoil geometry, and turbulence intensity influence the wake behaviors. For example, the vortex size, rotational direction, and shedding frequency [14]. On the other hand, the parameters governing the bursting of the bubbles as well as the proposed semi-empirical method for analysis bubble development were presented [15-17]. It is worth mentioning that laminar separation bubble size, location, and structure can vary in identical experiments at different facilities [18].

Several studies have shown the sensitivity of the aerodynamic performance of airfoils to flow conditions at low-Reynolds number [7]. For instance, lift coefficient, separation point, and stalling are drastically affected by a slight change in the airfoil geometry [19]. At low Reynolds number, separation and consequently stalling may negatively affect the aerodynamic performance and the vehicle structure load [20]. These are the reason which has triggered interest in finding an effective control method necessary to enhance the performance. Therefore, a thorough understanding of the laminar separation bubble is required.

Within the last decade, limited experimental and numerical studies have been performed to investigate flow structure and topology over an airfoil at a low Reynold number. Computational fluid dynamics (CFD) provide detailed setup analysis, cost-effective solutions, flow field examination, ease of data extraction, and lack of apparatus discrepancies to the study of low Reynolds number [5,18,2123]. Simulation involving laminar separation bubbles is more complex as compared to simple channel flows. Therefore, an absolute solution for reattached turbulent boundary layer and transition of the separated flow is essential [6]. 
The three main turbulence methods are Direct Numerical Simulation (DNS), Large Eddy Simulation (LES), and Reynolds-Averaged Navier-Stokes (RANS). Despite the capability of the Direct Numerical Simulation to obtain the resolution of the space and time scales, it requires enormous computing capability [24]. Thus, it is too costly for users [25]. Likewise, large eddy simulation is computationally expensive for complex unsteady phenomena because of the 3D nature of the eddies $[24,25]$. However, CFD solutions that are feasible and economical for low-Reynolds-number flows are rare [7].

Most of the turbulence models used to evaluate aerodynamic performance at relatively low Reynolds numbers, such as Spalart-Allmaras, $\mathrm{K}-\varepsilon$, and $\mathrm{K}-\omega$ were developed based on fully turbulent flow assumption [26]. This reason leads to unreliable results as opposed to the experimental data $[24,26]$. Another important reason is that fully turbulence models may not account for the occurrence of the laminar separation near the leading edge of the airfoil, leading to erroneous turbulent flow development, as well as the prediction of the laminar separation bubble [24].

Fully turbulent RANS type models do not predict the transition flow well [26-28]. Low-Reynoldsnumber turbulence models fail to anticipate transition and reattachment points despite resolving viscous sublayer well [29]. Correspondingly, tripping with an unsteady Reynolds-averaged NavierStokes (URANS) model neglects the transition patterns, which may lead to unacceptable results [30]. On the other hand, the semi-empirical approximate envelope (eN) method provides an unclear physical interpretation of three-dimensional (3-D) flows since it is based on linear-stability theory [31]. Furthermore, intermittency has been coupled to consider transition phenomena, which provides acceptable and cost-effective data [26,30,32,33]. However, the models are restricted to two-dimensional (2-D) flow analysis, and they depend on nonlocal terms, thus, omitting transition modeling [34].

A more recent transitional model known as the shear stress transport (SST) $\gamma-R e_{\theta}$ model, links the shear stress transport model with $\gamma$ and $R e_{\theta}$ transport equations [34,35]. This model is not depending on nonlocal terms and the intermittency is modified to allow better prediction of separation-induced transition [26,32,36]. Additionally, the model predicts the formation and structure of the separated bubble well [37-39]. Above all, the model is mostly used for external flow measurements at relatively high Reynolds number $\left(\operatorname{Re} \approx 10^{6}\right)$ and finite low Reynolds number [28].

It is a challenge to investigate the flow phenomenon because the detailed information of the flow is under-explored. In addition, there are only a handful of studies directed towards NACA 0015, most publications were on NACA 0012 [40]. Therefore, the importance of further studies will be crucial in many of the applications, such as unmanned aerial vehicles and wind turbines. The aim of this study is to examine the suitability of the shear stress transport (SST) model and provide complete aerodynamic characteristics. This study will also investigate the flow structure of NACA 0015 for a better understanding of low Reynolds number parameters such as separation, transition, reattachment, and laminar separation bubble.

\section{Governing Equations}

The numerical simulation of unsteady, laminar-turbulent flow around the airfoil was performed with a model known as the shear-stress transport (SST) $\gamma-R e_{\theta}$ model $[41,42]$.

The transport equation for the intermittency model is based on the following equation:

$$
\frac{\partial(\rho \gamma)}{\partial t}+\frac{\partial\left(\rho U_{j} \gamma\right)}{\partial x_{j}}=P_{\gamma 1}-E_{\gamma 1}+P_{\gamma 2}-E_{\gamma 2}+\frac{\partial}{\partial x}\left[\left(\mu+\frac{\mu_{\tau}}{\sigma_{f}}\right) \frac{\partial \gamma}{\partial x_{j}}\right]
$$


The sources for intermittency transport equation are defined as:

$$
\begin{aligned}
& P_{\gamma 1}=F_{\text {length }} \rho S\left[\gamma F_{\text {onset }}\right]^{C_{a 1}} \\
& E_{\gamma 1}=C_{e 1} P_{\gamma 1} \gamma
\end{aligned}
$$

Where $S$ defines the rate of deformation magnitude, $F_{\text {onset }}$ is a function of vorticity Reynolds number and is used to trigger the intermittency production, $F_{\text {length }}$ is an experimental correlation that defines the extent of the transition region. $R e_{\theta C}$ is the Reynolds number where the intermittency initially starts to rise in the flow near a bounded surface, and it happens ahead of the transition Reynolds number $\left(R e_{\theta t}\right) . R e_{\theta C}$ is related to $F_{\text {onset }}$.

The re-laminarization sources are defined as follows:

$$
\begin{aligned}
& P_{\gamma 2}=C_{a 2} \rho \Omega \gamma F_{\text {turb }} \\
& E_{\gamma 2}=C_{e 2} P_{\gamma 2} \gamma
\end{aligned}
$$

where $\Omega$ is the vorticity magnitude, it ensures that the intermittency remains zero in the laminar region as well as prediction of re-laminarization. $F_{\text {turb }}$ is used to turn off the re-laminarization sources in the viscous sublayer. The gamma value $(\gamma)$ normal to the wall is assigned zero whereas is equal to 1 at the inlet.

However, the model has consistently predicted the turbulent reattachment location too far downstream before modification, especially at lower turbulence intensity since turbulent kinetic energy, $k$, in the separating shear layer is small. It takes longer for turbulent kinetic energy to grow to large enough values for the boundary layer to reattach. Therefore, the local intermittency is allowed to exceed 1 to overcome this issue. Thus, turbulent kinetic energy grows faster, which enables the flow to reattach to the surface.

The modification of the transition model is as shown by the following equation:

$$
\gamma_{\text {sep }}=\min \left\{S_{1} \max \left[\left(\frac{R e_{\mathrm{v}}}{2.193 \operatorname{Re}_{\theta c}}\right)-1,0\right] F_{\text {reattach }}, 5\right\} F_{\theta t}
$$

$S_{1}$ is a constant that controls the size of the separation bubble. $F_{\text {reattach }}$ turns off the modification once the viscosity ratio is large enough to cause the reattachment. In addition, with the flexibility of the current equation, the destruction term in the turbulent kinetic energy equation is controlled so as not to exceed fully turbulent value.

The transport equation for the $\widetilde{R e}_{\theta t}$ is based on the following equation:

$$
\frac{\partial\left(\rho \widetilde{R e}_{\theta t}\right)}{\partial t}+\frac{\partial\left(\rho U_{j} \widetilde{R e}_{\theta t}\right)}{\partial x_{j}}=P_{\theta t}+\frac{\partial}{\partial x_{j}}\left[\sigma_{\theta t}\left(\mu+\mu_{t}\right) \frac{\partial \widetilde{R e}_{\theta t}}{\partial x_{j}}\right]
$$

This equation helps to pass the freestream values to the boundary layer using only a local formulation. $R e_{\theta t}$ relies on the incidence variables such as the turbulence intensity and the pressure gradient. 
The source term is defined as:

$P_{\theta t}=c_{\theta t} \frac{\rho}{t}\left(R e_{\theta t}-\widetilde{R e}_{\theta t}\right)\left(1.0-F_{\theta t}\right)$

$P_{\theta t}=\frac{500 \mu}{\rho U^{2}}$

where $t$ is a time scale, $F_{\theta t}$ is employed to disable the source term in the $\mathrm{BL}$ and allow $\widetilde{R e}{ }_{\theta t}$ to propagate from the freestream into the BL. $F_{\theta t}$ is assigned as 0 in the freestream and 1 in the boundary layer. $\widetilde{R e}_{\theta t}$ is the transmitted scalar value of $R e_{\theta t}$ and zero flux is assigned at the wall boundary.

The two transition equations discussed above are linked with the SST turbulence model using effective intermittency by modifying the turbulent kinetic energy source terms. The modified shear stress transport (SST) $k-\omega$ model that comprises of turbulent kinetic energy, $k$, and specific dissipation rate, $\omega$ transport equations is given by the following:

$\frac{\partial}{\partial t}(\rho k)+\frac{\partial}{\partial x_{j}}\left(\rho u_{j} k\right)=\widetilde{P}_{k}-\widetilde{D}_{k}+\frac{\partial}{\partial x_{j}}\left[\left(\mu+\sigma_{k} \mu_{t}\right) \frac{\partial k}{\partial x_{j}}\right]$

$\frac{\partial}{\partial t}(\rho \omega)+\frac{\partial}{\partial x_{j}}\left(\rho u_{j} \omega\right)=\alpha \frac{P_{k}}{v_{t}}-D_{\omega}+C d_{\omega}+\frac{\partial}{\partial x_{j}}\left[\left(\mu+\sigma_{k} \mu_{t}\right) \frac{\partial \omega}{\partial x_{j}}\right]$

Where $P_{k}$ and $D_{k}$ are the production and the destruction terms from the turbulent kinetic energy equation in the original SST turbulence model, respectively.

The final modification is blending function $F_{1}$ that is responsible for switching between the $k-\omega$ and $k-\varepsilon$ models. Thus, switching between 1 and 0 values. The equations used to define $F_{1}$ were intended solely in the turbulent boundary layers. Therefore, $F_{1}$ is redefined to allow a value of 1 in a laminar boundary layer.

\section{Method Validation}

\subsection{Mesh Analysis}

The model used in this study is NACA 0015 airfoil of chord length $0.15 \mathrm{~m}$. It has been designed with a sharp trailing edge to allow for a better-structured mesh. Two-dimensional analysis was considered since many 2-D computational investigations are available in the literature for results comparison. Likewise, two-dimensional analysis provides relatively accurate results and saves computational time.

The pressure-velocity integrating scheme used is coupled, the gradients were calculated based on the least-squares cell method. A second-order upwind discretization scheme was utilized to solve all the equations. Finally, bounded second-order implicit has been selected to set an appropriate time-dependent solution formulation.

A Fixed time-stepping scheme was used to evaluate the simulation, $5.0 \times 10^{-5}$ was found sufficient for different cases. This scheme has been reaffirmed with drag and lift coefficient plots. Moreover, Double precision was enabled so that truncation error is reduced. The residual for all equations is set to none, this allows the simulation results match the experimental data.

The computational domain (Figure 1) was 30c upstream, above and below the airfoil surface. Additionally, 60c downstream was considered to capture the wake region and ensure uniform freestream condition at the inlet. The mesh is composed of 6 parts. The first shell is the partition for 
the finest mesh near the airfoil walls since it is the closest to the boundary layer region. This assists in terms of the boundary layer resolution. The rest of the shells are sub-divided next to each other following the first shell. The division provides an easy way to have a finer and well-distributed mesh around the area of most interest. Structured C-H grid topology was selected such as shown in Figure 2.

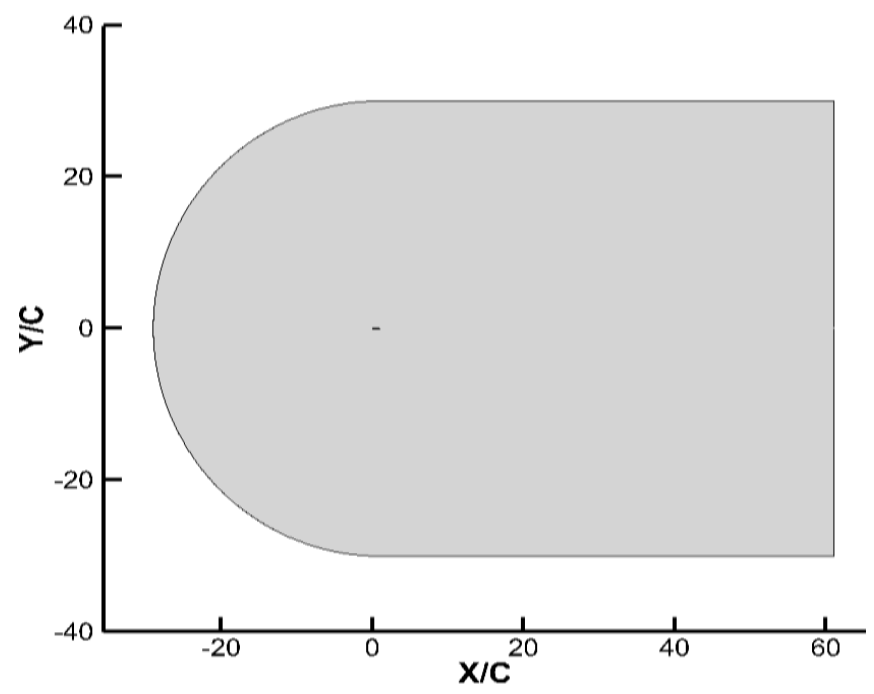

Fig. 1. Diagram of the domain used in the present work

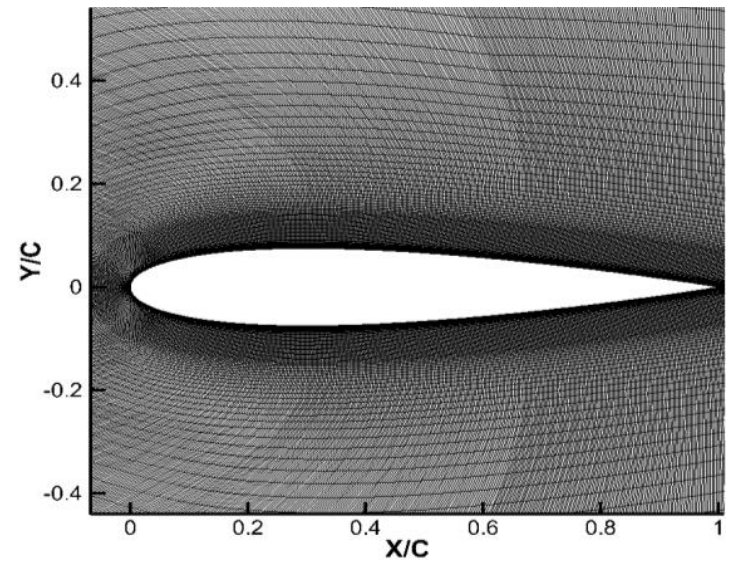

(a)

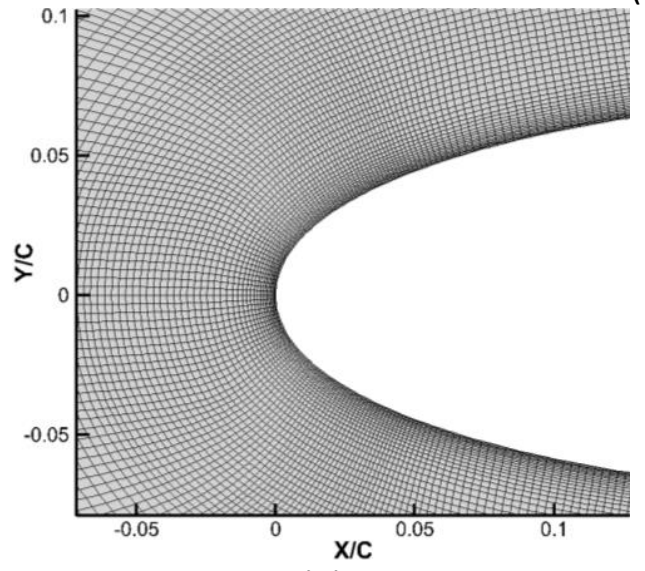

(b)

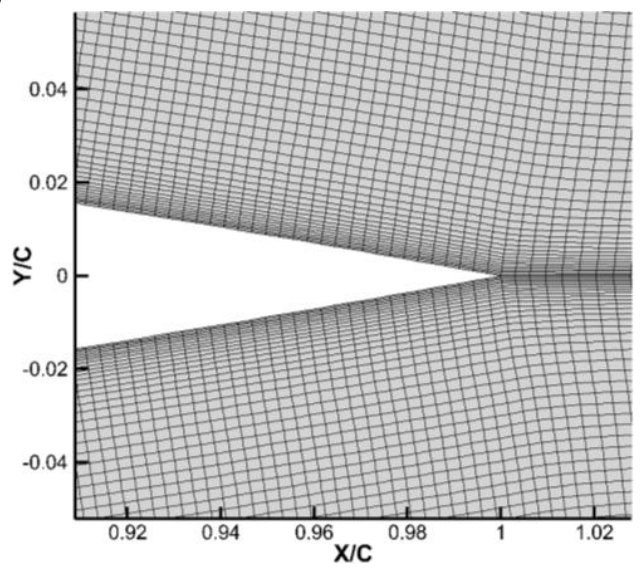

(c)

Fig. 2. (a) C-type grid topology for the NACA 0015 airfoil used in the current study (b) Close-up view of the mesh at the leading edge (c) Close-up view of the mesh at the trailing edge 
Several cases were analyzed based on the number of the grids (see Figure 3 ). The mesh for case 1 has 72220 grids, whereas case 2 and case 3 have 144440 and 288880, respectively. Case 3 is the finest, while Case 2 has a finer resolution than case 1, which was done by doubling the mesh. For both cases, the distance from the first row of cells to the airfoil wall is set to 0.8 with wall grid expansion of 1.2 and this correspond to $\mathrm{y}+$ of 0.8 . The required $\mathrm{y}+$ for the SST $\gamma-\operatorname{Re}_{\theta}$ model is less than 1 . This provides better resolution near the airfoil walls hence laminar and transition boundary layers are expressed well.

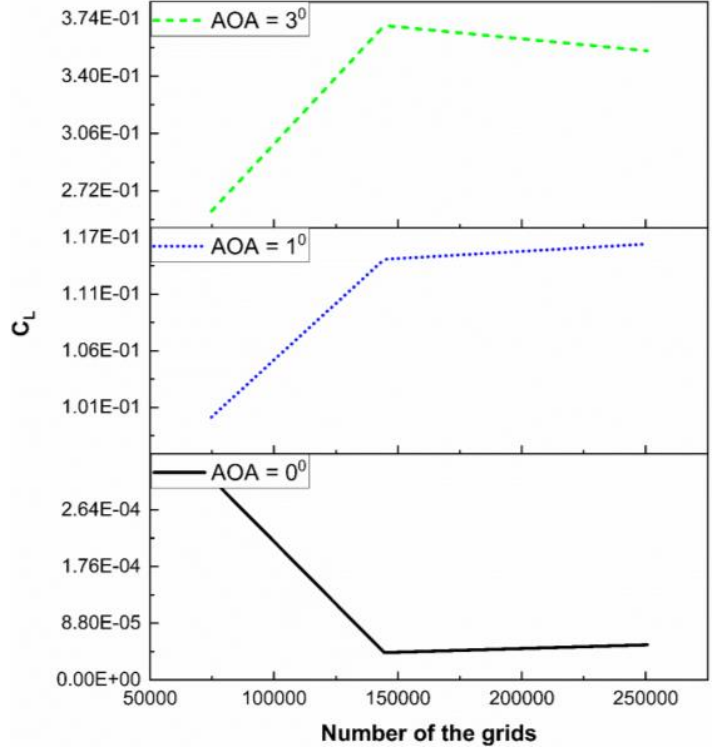

(a)

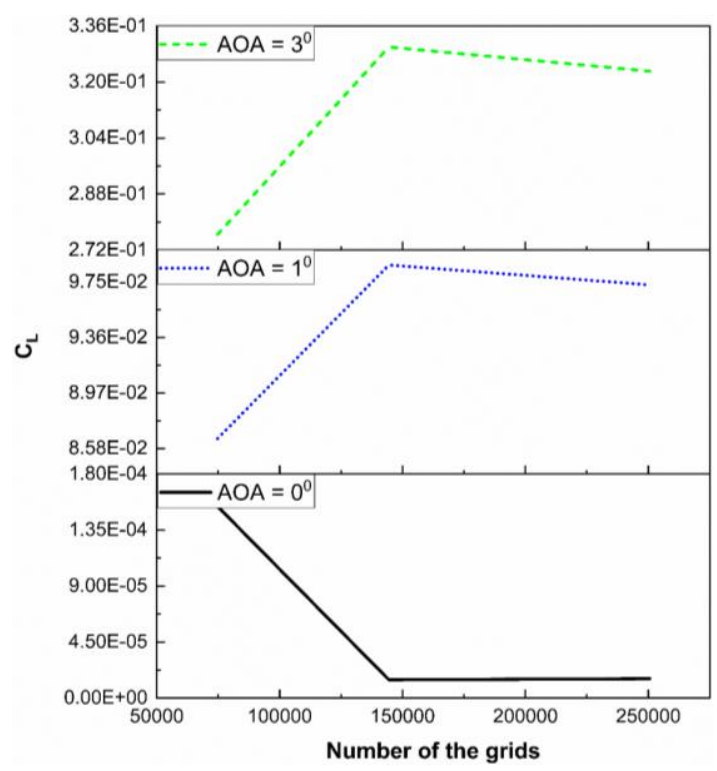

(b)

Fig. 3. (a) Mesh independent study for $\operatorname{Re}=8.4 \times 10^{4}$ (b) Mesh independent study for $\operatorname{Re}=1.7$ $\times 10^{5}$

Overall, the results summarized in Figure 3 show that case 2 and case 3 perform reasonably well. However, case 2 is the most suitable for the flow characteristics analysis in the next section. Case 2 has fewer grids compared to case 3 hence less computational time. Moreover, it has relatively the same results as the finest mesh.

\subsection{Validation}

Figure 4 shows the comparison of the present lift and drag coefficients of NACA 0015 with those obtained from the experimental data $[43,44]$. The results showed acceptable variations between the present study and the experimental data. However, it is worth mentioning that the turbulence viscosity ratio of the experiment was not mentioned in the literature $[43,44]$. In the current computational analysis, the turbulent intensity of $2 \%$ was kept the same as in the experimental work [43].

Note that the experimental data were provided at relatively lower Reynold number $(\operatorname{Re}=1.66 \times$ $10^{5}$ ) whereas the other experimental work and the present study were presented at slightly higher Reynolds number $\left(\operatorname{Re}=1.7 \times 10^{5}\right)[43,44]$. On the other hand, they were all reported at $\operatorname{Re}=8.4 \times$ $10^{4}$.

For both $\operatorname{Re}=8.4 \times 10^{4}$ and $\operatorname{Re}=1.7 \times 10^{5}$, lift and drag coefficient shows allowable trend through all the angles of attack. The results are agreeable, especially at low angles of attack i.e., $0 \leq \alpha \leq 2$, then a slight fluctuation is observed all over the experimental data. Both the SST $\gamma-R e_{\theta}$ model and the experimental work fairly predict a decrease of the drag coefficient as the Reynolds number is 
increased from $8.4 \times 10^{4}$ to $1.7 \times 10^{5}$. Likewise, the drag coefficient increased for $\operatorname{Re}=1.7 \times 10^{5}$ as the angle of attack increased. For the lift coefficient, both the present study and the experiments showed an increase as the Reynolds number and angle of attack is increased. Overall, the SST $\gamma-R e_{\theta}$ model has sufficiently predicted the patterns of lift and drag data. Likewise, good agreement between experimental and numerical results was also observed by other authors $[26,45]$. Therefore, the numerical model is considered sufficient to examine the flow structure and physics of NACA 0015 airfoil at a low Reynolds number.

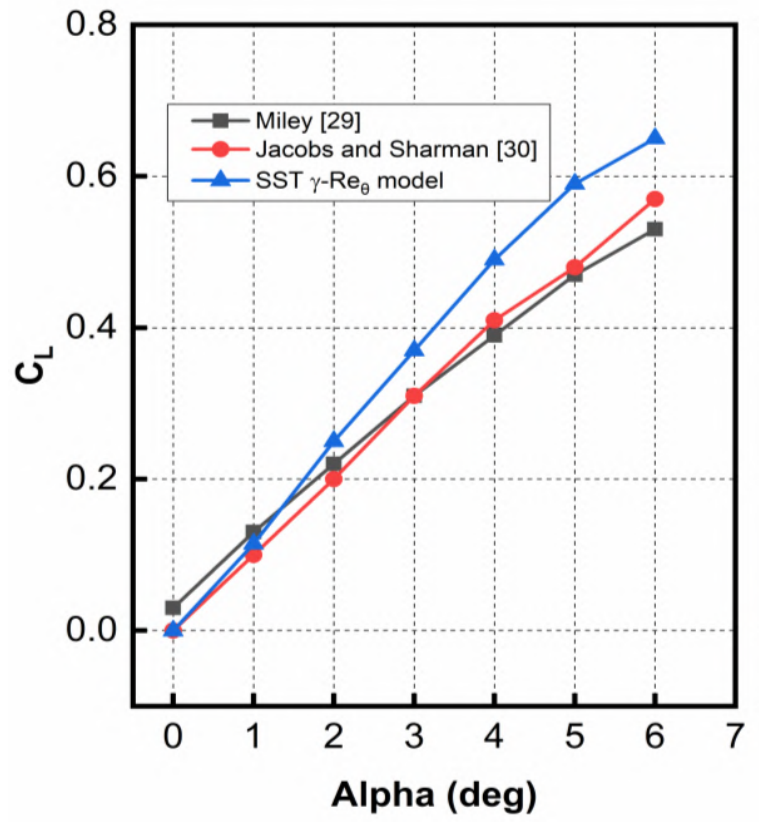

(a)

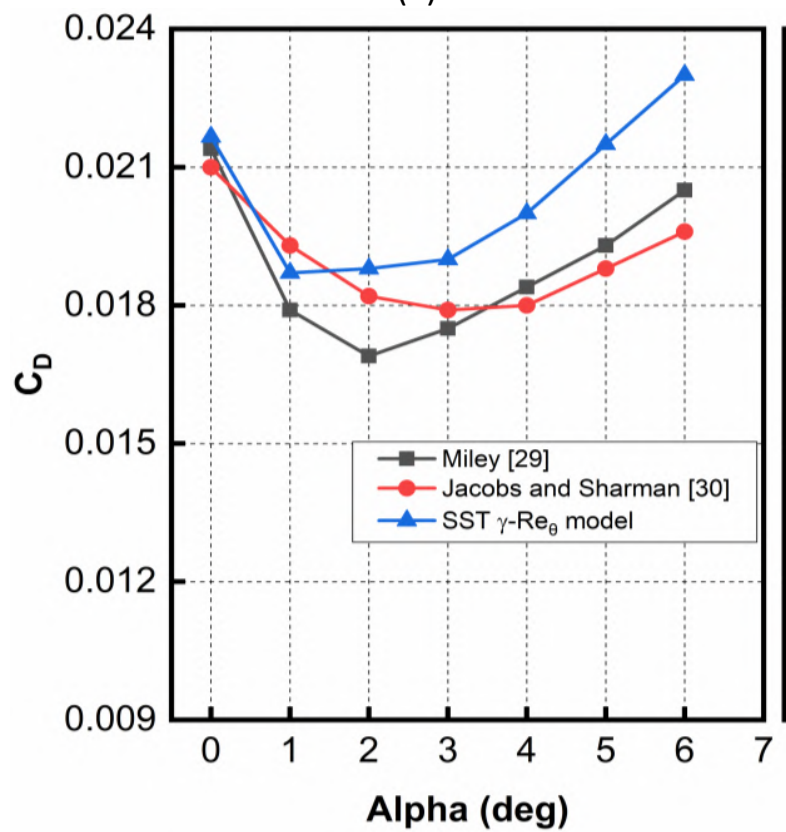

(c)

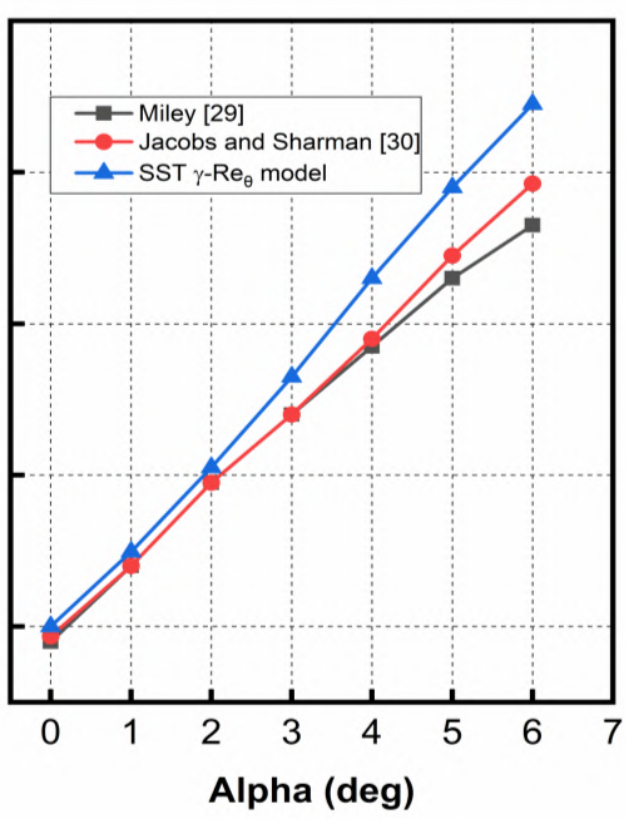

(b)

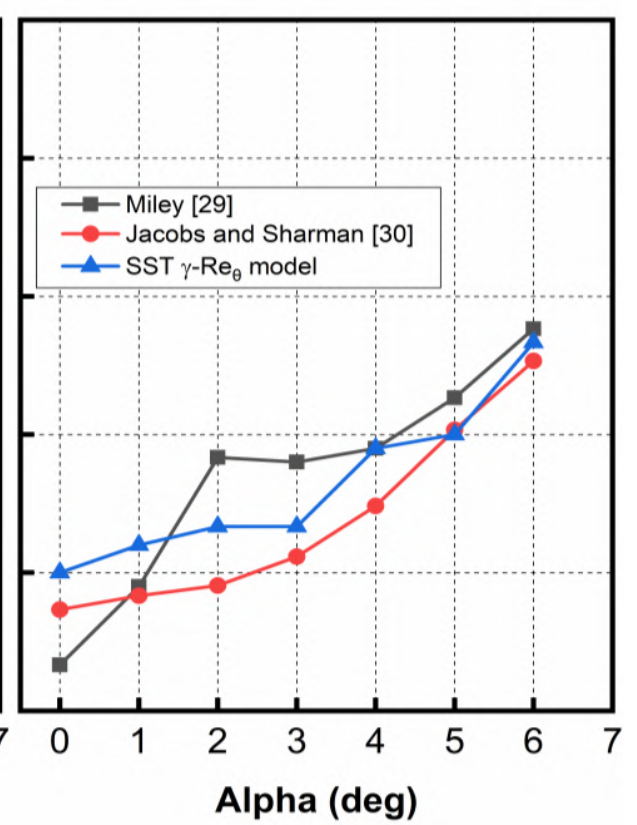

(d)

Fig. 4. Comparison of experimental data and the predicted values at $\operatorname{Re}=8.4 \times 10^{4}(\mathrm{a}, \mathrm{c})$ and $\operatorname{Re}=1.7 \times 10^{5}(\mathrm{~b}, \mathrm{~d})$ 


\section{Mean Aerodynamic Characteristics}

At low Reynolds number, the flow is mostly laminar near the leading edge and separate downstream because of natural instability in the boundary layer. The flow experiences a transition to turbulent flow and reattaches to the surface to form the laminar separation bubble. The bubble may grow or shrink depending on the conditions of the flow over the airfoil surface. Detailed investigation on low Reynolds number is needed to solve for the physics of the complex flow.

In this study, numerical investigation for case 2 (mesh with 144440 grids) is performed using the SST $\gamma-R e_{\theta}$ model. The results are generated at several Reynolds number and angles of attack. Reynolds numbers of $8.4 \times 10^{4}$ and $1.7 \times 10^{5}$ are considered in this study and angles of attack spanning from 0 to 3 degrees.

The flow direction for each image is from left to right. Separation points are denoted as ' $S$ ', transition as ' $T$ ', and reattachment point as ' $R$ '. In addition, a friction coefficient plot is used to verify the separation, transition, and reattachment points. Separation and reattachment points are identified at the intersection of the friction coefficient curve with the horizontal axis, whereas the transition point is stipulated as the negative peak of the plot.

Increasing Reynolds number from $8.4 \times 10^{4}$ to $1.7 \times 10^{5}$ slightly moved the separation point upstream on the suction side (Figure 5 and Figure 6). This pattern was also mentioned by another author [46]. The laminar separation bubble located in the adverse pressure gradient can be categories into a short and long bubbles. The bubbles presented in Figure 7 are of the long type since it covers approximately $35 \%$ to $50 \%$ of the chord length. The negative skin friction indicates the reversed flow regime, whereas the size of the bubble is measured between the points of intersection with the horizontal axis (Figure 6). In most cases, the flow attaches near the trailing edge on the upper surface of the airfoil. Thus, fully turbulent flow is not adequately observed on the suction side. This was witnessed at $0^{\circ} \leq \alpha \leq 3^{\circ}$ (Figure 7(b) to Figure 7(h)).

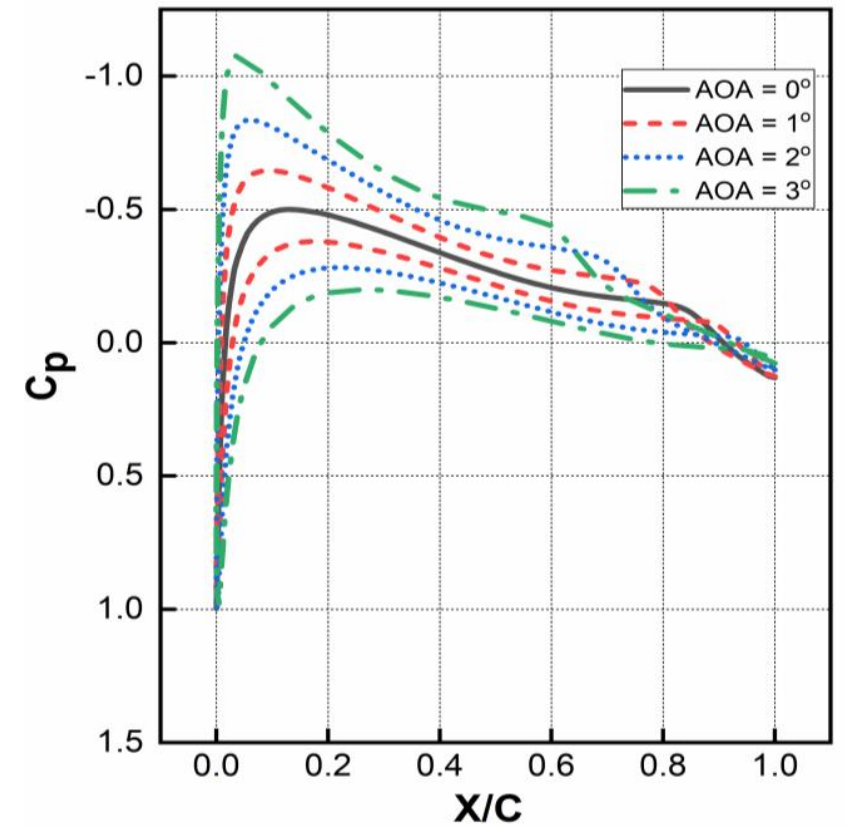

(a)

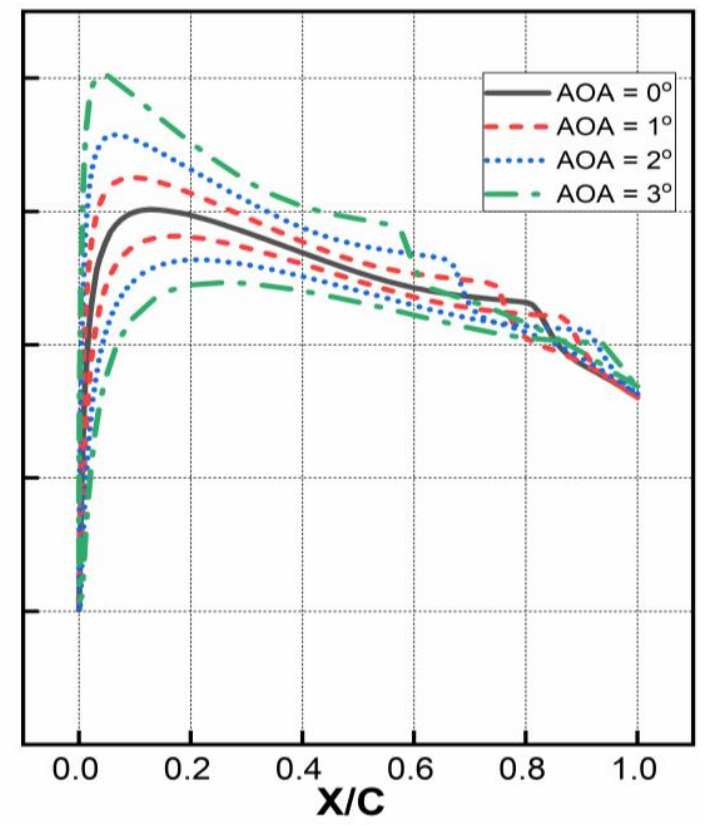

(b)

Fig. 5. Pressure coefficient distribution on the NACA 0015 at (a) $\operatorname{Re}=8.4 \times 10^{4}$ and (b) $\operatorname{Re}=1.7 \times$ $10^{5}$ 


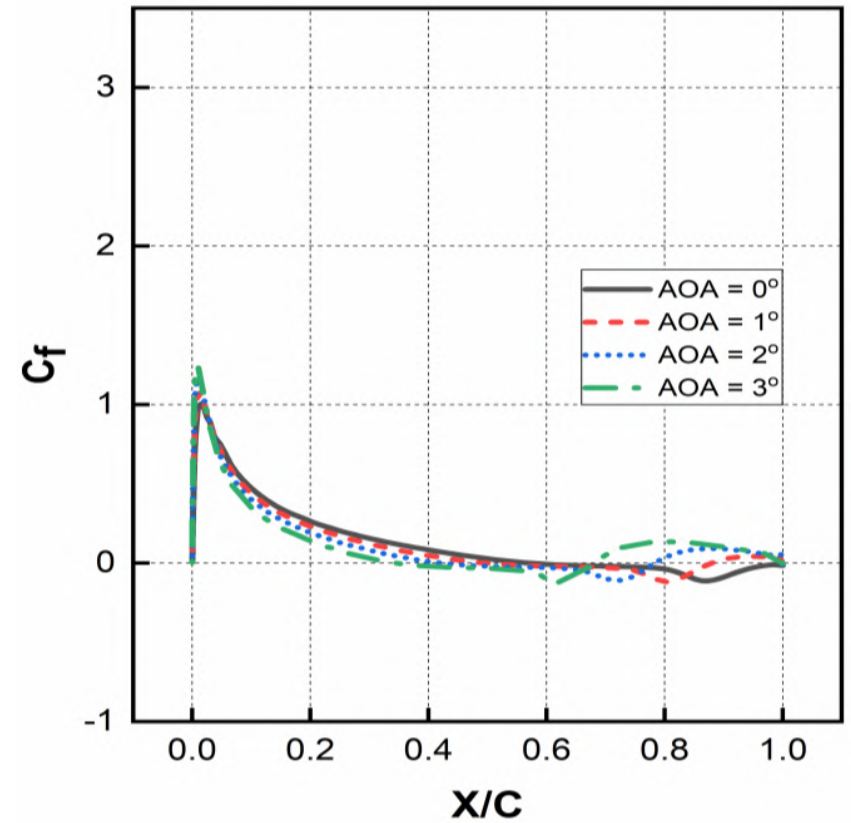

(a)

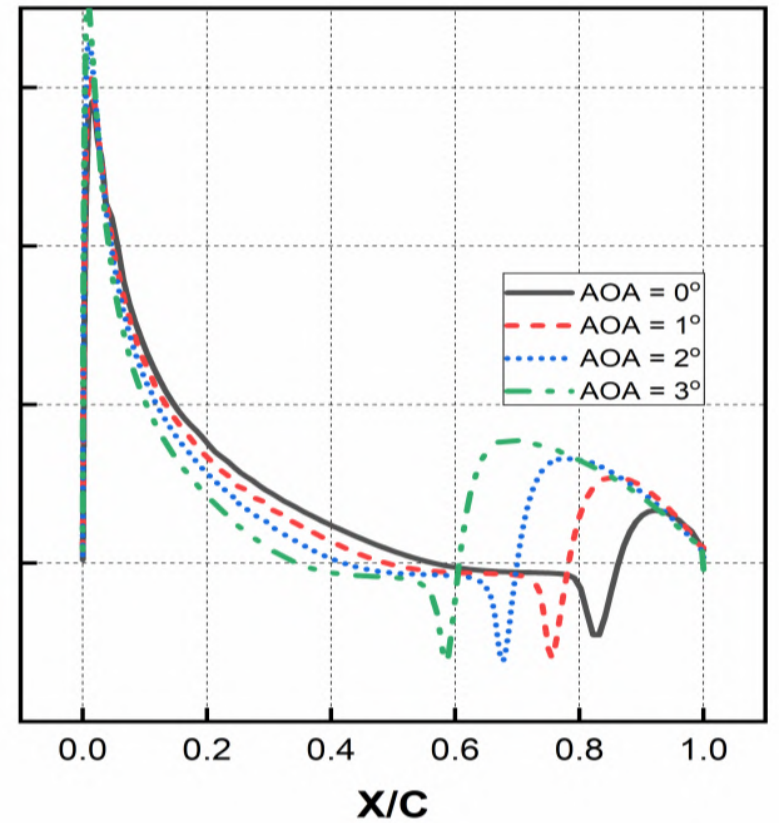

(b)

Fig. 6. Surface skin friction distribution on the suction side of NACA 0015 at (a) Re $=8.4 \times 10^{4}$ and (b) $\operatorname{Re}=1.7 \times 10^{5}$

Contrarily, the separation point remained the same at $\alpha=3^{\circ}$ (Figure 7(g) and Figure $7(\mathrm{~h})$ ). Likewise, it can be observed that both separation, transition, and reattachment points shifted towards the leading edge whenever the angle of attack is increased. At $\alpha=1^{\circ}$ (Figure 8(a)), the flow separates at roughly $0.498 \mathrm{c}$, however, the point of separation moved to about $0.345 \mathrm{c}$ at $\alpha=3^{\circ}$. These trends were also seen by many authors $[4,32,47,48]$. Laminar separation bubble is formed as the flow reattaches to the surface. The formation of the laminar bubble on the airfoil's suction side is observed at $\operatorname{Re}=8.4 \times 10^{4}$ and $1.7 \times 10^{5}$ (Figure $7(\mathrm{~b})$ to Figure $7(\mathrm{~h})$ ). The flow experiences separation without reattachment at $\mathrm{Re}=8.4 \times 10^{4}$ (Figure 7(a)).

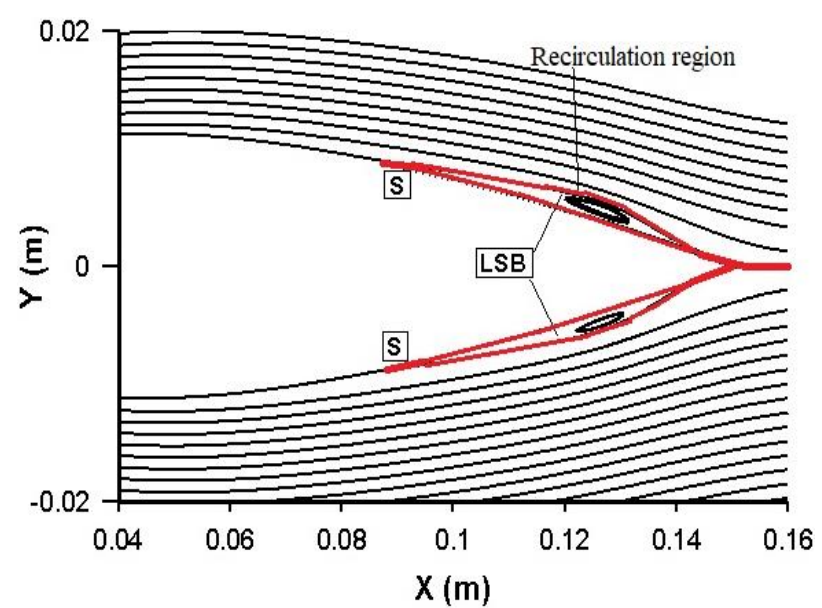

(a) $\operatorname{Re}=8.4 \times 10^{4}, 0 \mathrm{deg}$

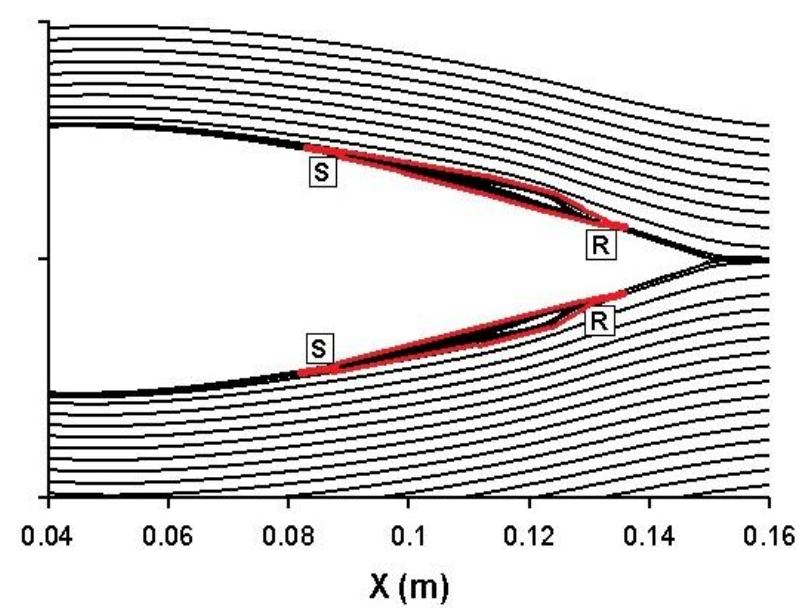

(b) $\operatorname{Re}=1.7 \times 10^{5}, 0 \mathrm{deg}$ 


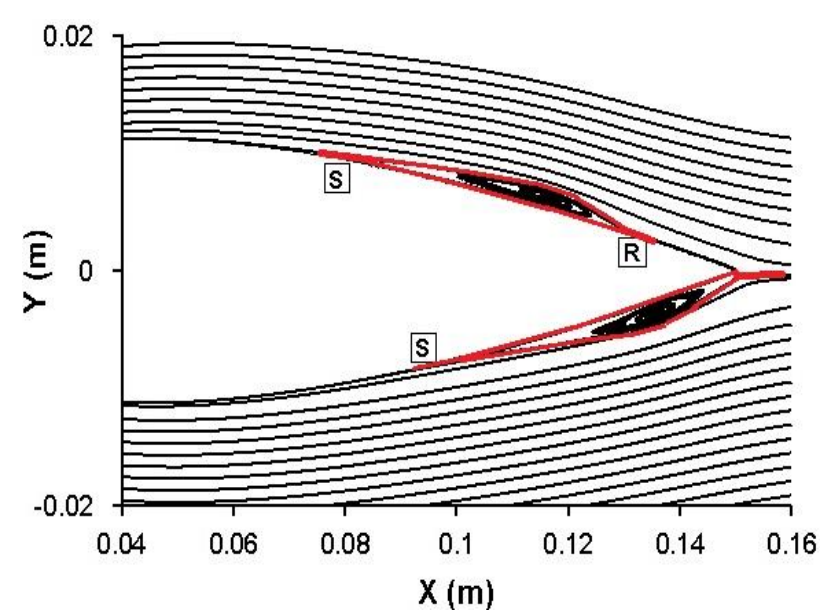

(c) $\operatorname{Re}=8.4 \times 10^{4}, 1 \mathrm{deg}$

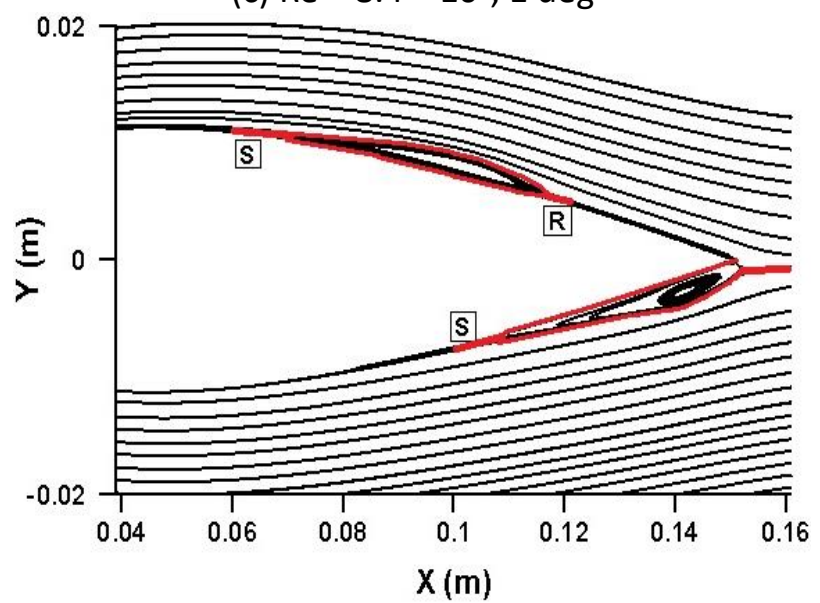

(e) $\operatorname{Re}=8.4 \times 10^{4}, 2 \mathrm{deg}$

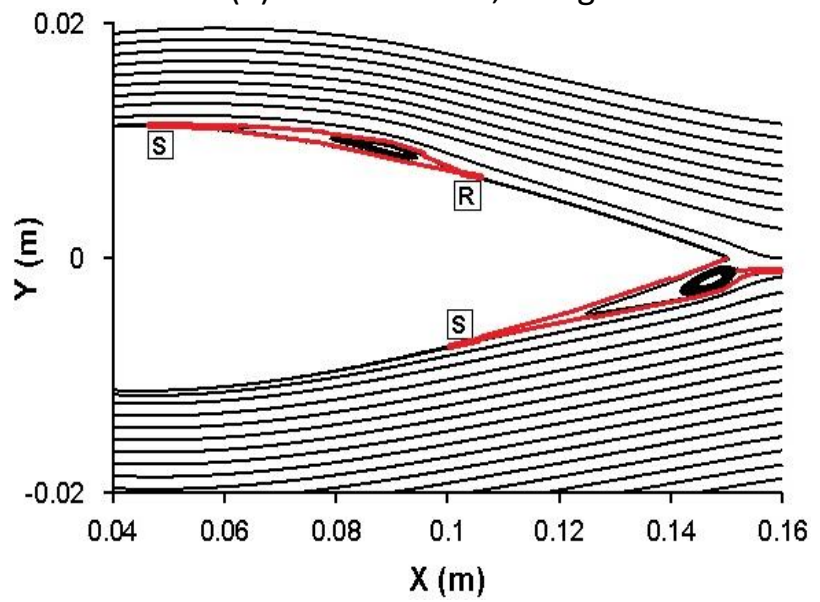

(g) $\operatorname{Re}=8.4 \times 10^{4}, 3 \mathrm{deg}$

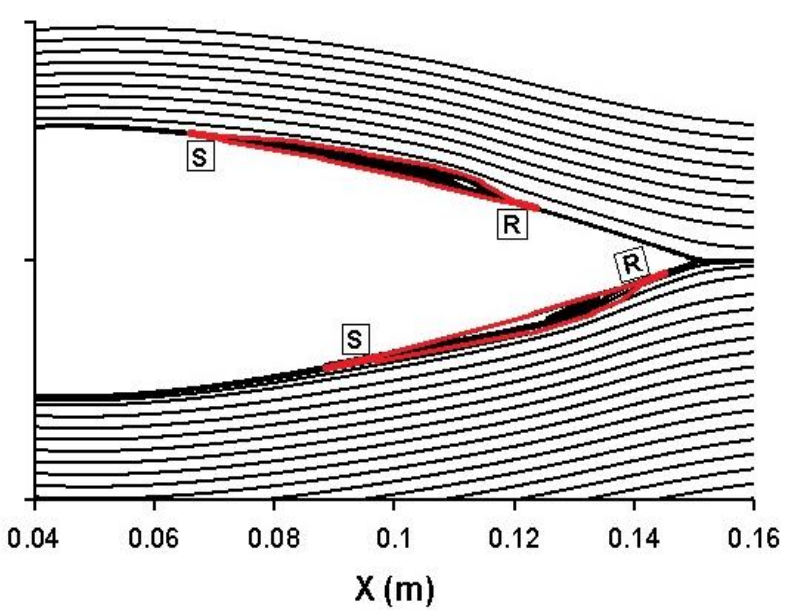

(d) $\operatorname{Re}=1.7 \times 10^{5}, 1 \mathrm{deg}$

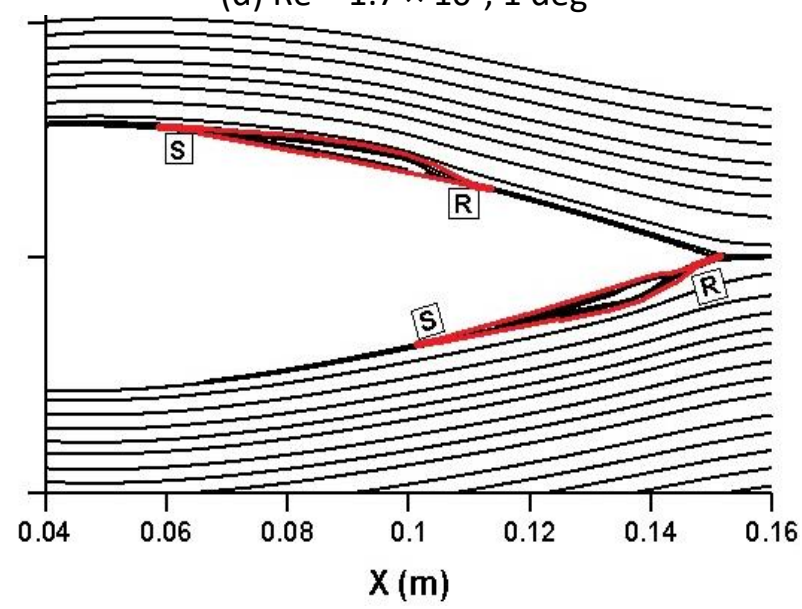

(f) $\operatorname{Re}=1.7 \times 10^{5}, 2 \mathrm{deg}$

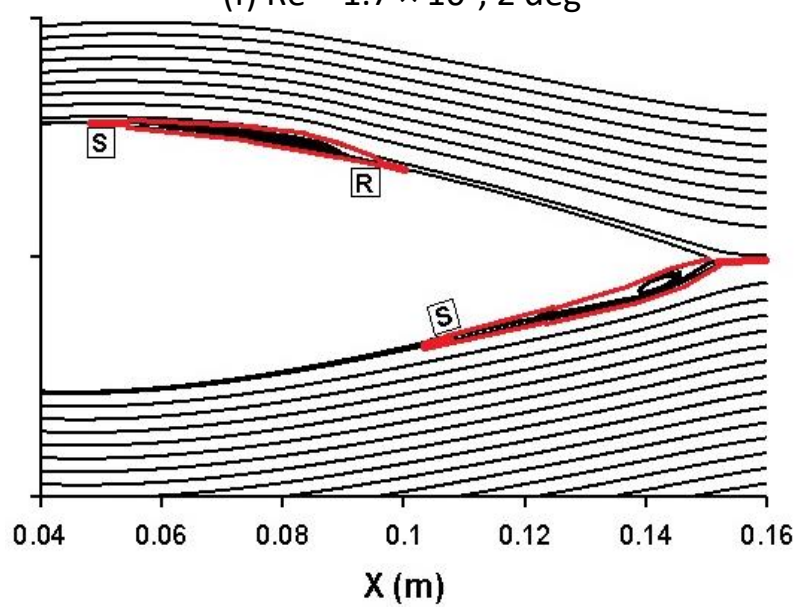

(h) $\operatorname{Re}=1.7 \times 10^{5}, 3 \mathrm{deg}$

Fig. 7. Close-up view of the streamline computed on the NACA 0015

On the pressure side, the laminar bubble is seen to move toward the trailing edge at relatively the same size as the angle of attack increases (Figure 7). The separation point moved from 0.57c to $0.723 \mathrm{c}$ at $\alpha=0^{\circ}$ and $\alpha=3^{\circ}$ respectively (Figure 8(c)). Laminar separation bubble was formed at $\operatorname{Re}$ $=1.7 \times 10^{5}$, except at $\alpha=3^{\circ}$ (Figure 7(b), Figure 7(d), and Figure 7(f)). The flow experiences separation without reattachment for all angles of attack at $\operatorname{Re}=8.4 \times 10^{4}$ (Figure 7(a), Figure 7(c), Figure 7(e) and Figure 7(g)). 


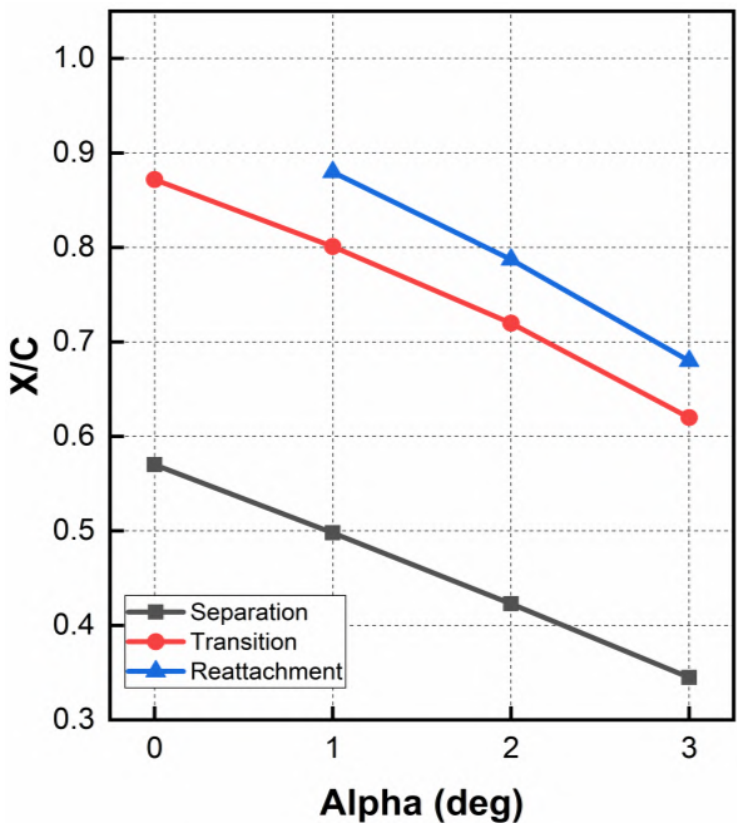

(a)

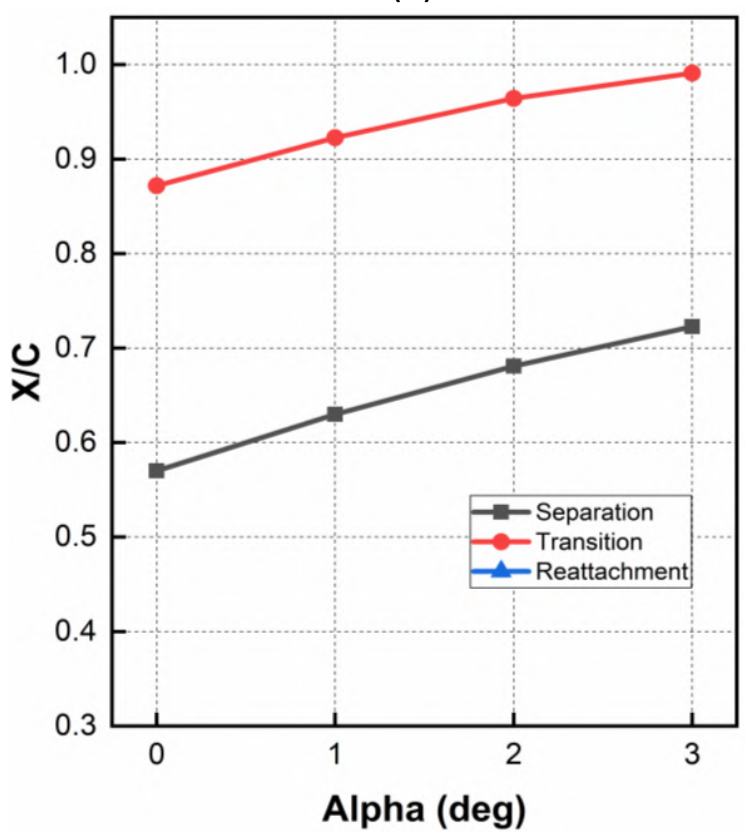

(c)

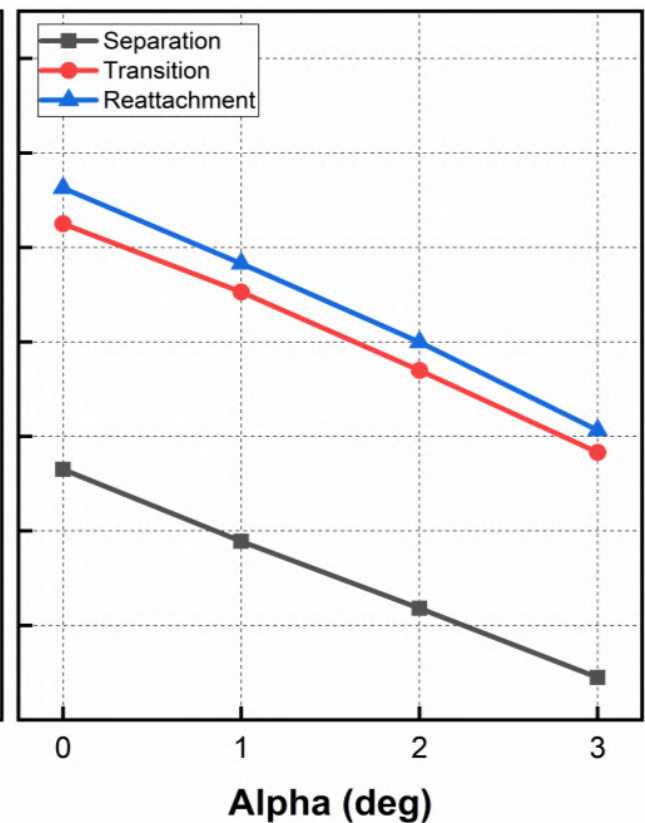

(b)

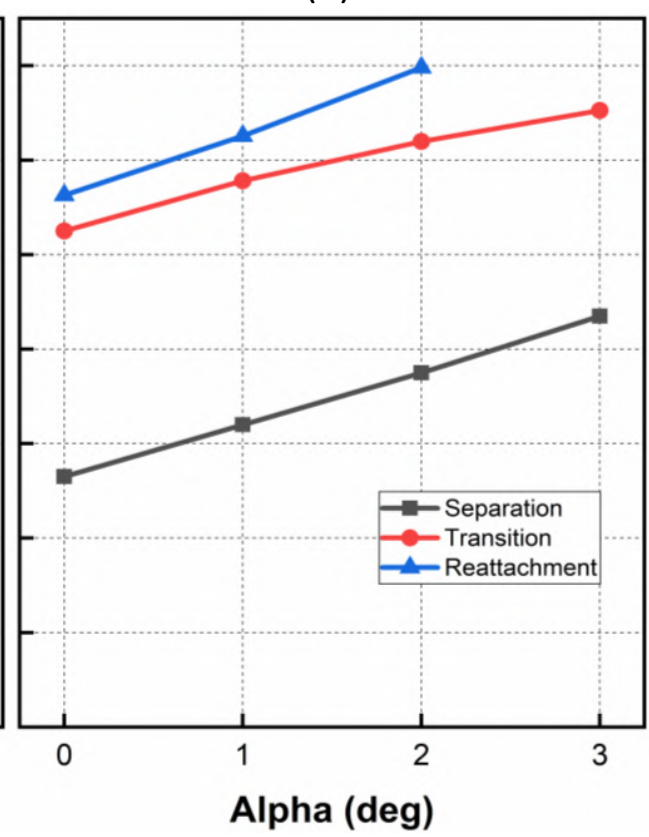

(d)

Fig. 8. Mean location of separation, transition, and reattachment points on the $(a, b)$ suction and $(c, d)$ pressure side of NACA 0015

Figure 6 presents a flow reversal region immediately after the separation point. The reversal flow region relocates upstream whenever the angle of attack is increased. This region captures the inner part of the laminar separation bubble. The reversed flow is basically due to an adverse pressure gradient. Whenever the adverse pressure gradient is more than momentum transport from the freestream, the flow would be forced to move against the incidence stream. This part of the laminar separation bubble is unstable and usually transit to turbulence at times. This can be further clarified by the averaged velocity profile in Figure 9 . At $\alpha=3^{\circ}$ (Figure 7(a)), the vortex generated due to the flow reversal (rolling-up vortex) is combined with the one from the pressure side thus forming a more complex vortices near the trailing edge (wake region). 


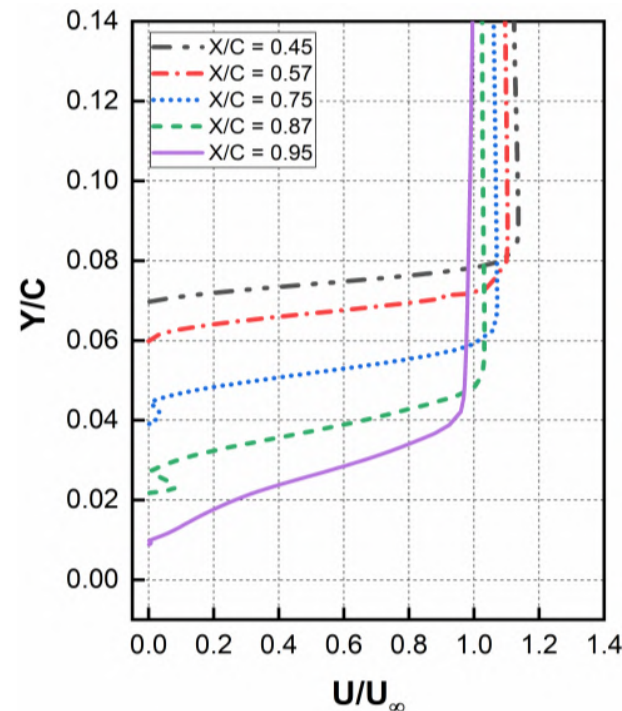

(a) $\operatorname{Re}=8.4 \times 10^{4}, 0 \mathrm{deg}$

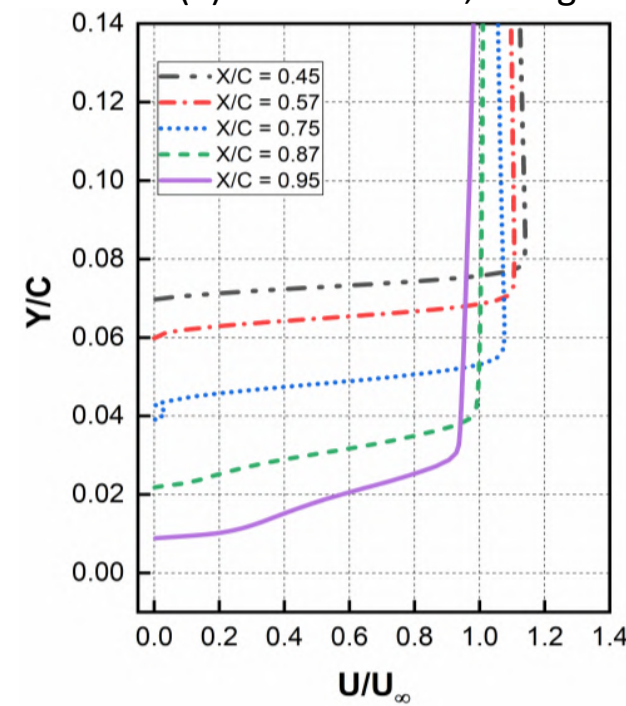

(d) $\operatorname{Re}=1.7 \times 10^{5}, 0 \mathrm{deg}$

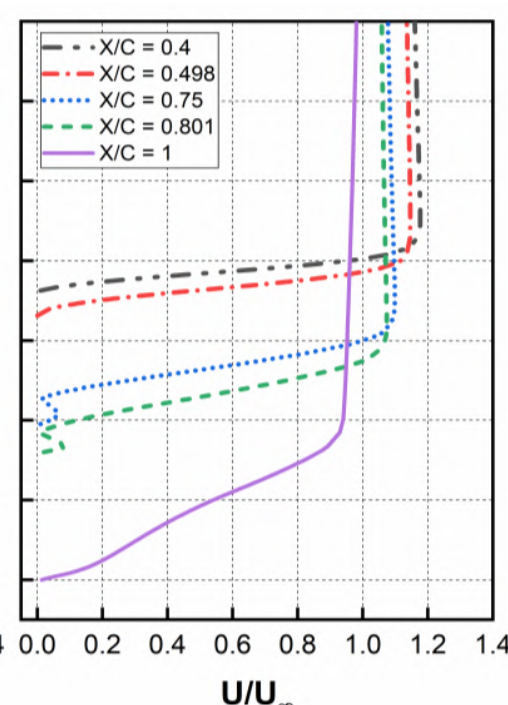

(b) $\operatorname{Re}=8.4 \times 10^{4}, 1 \mathrm{deg}$

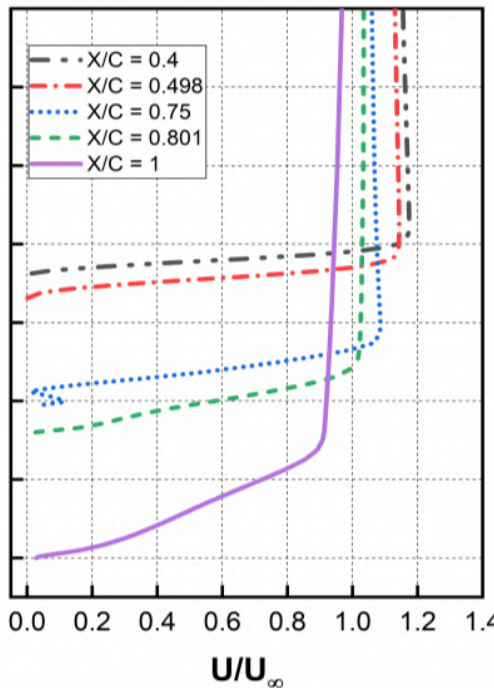

(e) $\operatorname{Re}=1.7 \times 10^{5}, 1 \mathrm{deg}$

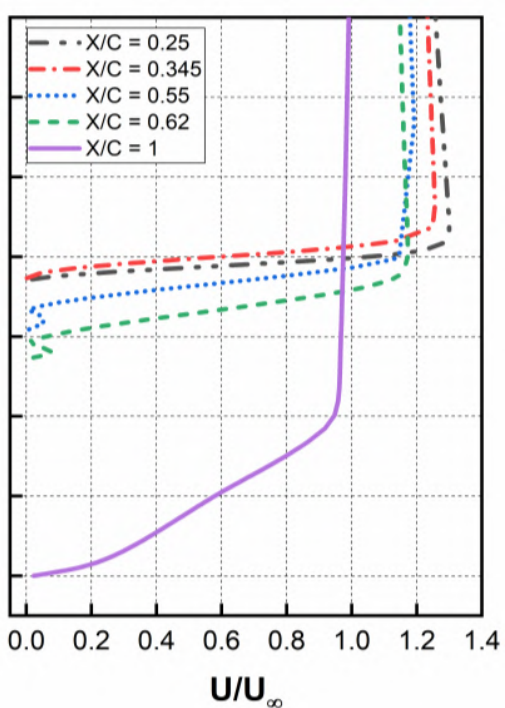

(c) $\operatorname{Re}=8.4 \times 10^{4}, 3 \mathrm{deg}$

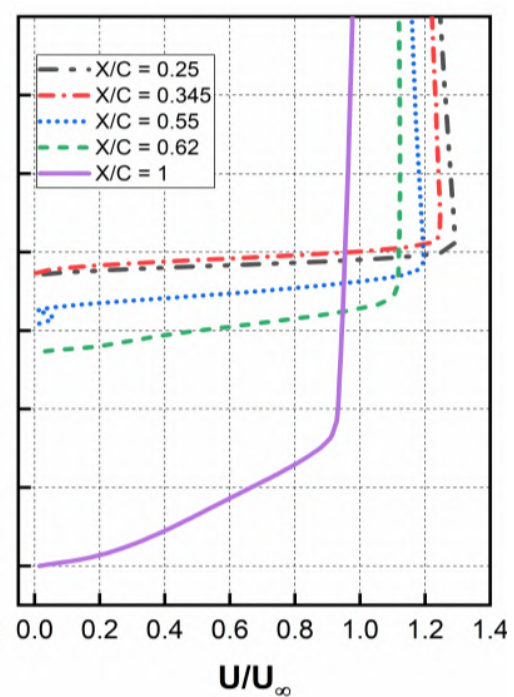

(f) $\operatorname{Re}=1.7 \times 10^{5}, 3 \mathrm{deg}$

Fig. 9. Mean velocity profile on the suction-surface of NACA 0015

The shear-layer patterns across various regions of the flow are clearly shown in Figure 9. The result reaffirms the location and size of the bubble over the airfoil surface. The separation point is indicated by a sudden zero velocity gradient near the wall surface, whereas the flow reversal is illustrated by the curving of the profile near the wall towards the leading edge. The profile provided for five chordwise locations along the airfoil suction side clearly shows the flow development stages. With increasing angle of attack, the velocity profiles shrank towards the leading edge, consequently, verifies the influence of the angle of attack on the separation point.

Therefore, results on the suction side suggest that with increasing Reynolds number and angle of attack, the laminar separation bubble propagates towards the leading edge causing early transition and reattachment at some instances. However, with an increasing angle of attack, the separation point moves downstream on the pressure side [38]. Majority of the cases, bubbles are produced at both sides of the airfoil for $\operatorname{Re}=1.7 \times 10^{5}$ except $\alpha=3^{\circ}$ (Figure 7(h)). No bubbles were formed at $\operatorname{Re}$ $=8.4 \times 10^{4}$ at all the angles of attack $0^{\circ} \leq \alpha \leq 3^{\circ}$ on the pressure side. Moreover, the influence of the angle of attack on the laminar separation bubble characteristics is higher as compared to the Reynolds number. 


\section{Conclusions}

In this study, the analysis of the flow characteristics of NACA 0015 airfoil is designed and analyzed at relatively low Reynolds number $\left(8.4 \times 10^{4}\right.$ and $\left.1.7 \times 10^{5}\right)$ and angles of attack $\left(0^{\circ} \leq \alpha \leq 3^{\circ}\right)$. Shearstress transport (SST) $\gamma$-Re $\theta$ model was employed to perform detail analysis associated with the flow field.

Results show that long laminar separation bubbles were found on the suction side at both Reynolds numbers except at $\alpha=0^{\circ}$. It was found that laminar separation bubble influences both the pressure distribution and skin friction distribution of an airfoil. Two different flow configurations were presented namely, laminar separation bubble with reattachment and laminar separation bubble without reattachment.

Laminar separation bubble with reattachment were found on the suction side at all angles of attack $\left(0^{\circ} \leq \alpha \leq 3^{\circ}\right)$ for $\operatorname{Re}=1.7 \times 10^{5}$. The flow did not reattach to the surface and hence no bubble formed on the suction side at $\alpha=0^{\circ}$ for $\mathrm{Re}=8.4 \times 10^{4}$. In addition, no bubbles were formed on the pressure side at $\operatorname{Re}=8.4 \times 10^{4}$ at all the angles of attack $0^{\circ} \leq \alpha \leq 3^{\circ}$. Bubbles are produced on the pressure side for $\operatorname{Re}=1.7 \times 10^{5}$ except for $\alpha=3^{\circ}$. Regardless of the Reynolds number, laminar separation bubble without reattachment was formed on the pressure side at $\alpha=3^{\circ}$.

Overall, separation, transition, and reattachment points shift upstream with increasing Reynolds number and angles of attack on the suction side, in addition, shrinking the size of the laminar bubble. However, On the pressure side, the laminar bubble moved toward the trailing edge at relatively the same size as the angle of attack increases.

\section{Acknowledgement}

The research was supported by Ministry of Education (MOE) through Fundamental Research Grant Scheme (FRGS/1/2018/TK09/UIAM/03/4). We would also like to thank financial support by IIUM under the KOE Postgraduate Tuition Fee Waiver Scheme 2019 (TFW2019).

\section{References}

[1] Kurelek, John W., Burak A. Tuna, Serhiy Yarusevych, and Marios Kotsonis. "Three-Dimensional Development of Coherent Structures in a Two-Dimensional Laminar Separation Bubble." AIAA Journal 59, no. 2 (2021): $493-505$. https://doi.org/10.2514/1.J059700

[2] Singh, N. K. "Instability and Transition in a Laminar Separation Bubble." Journal of Applied Fluid Mechanics 12, no. 5 (2019): 1511-1525. https://doi.org/10.29252/jafm.12.05.29607

[3] ElJack, Eltayeb. "High-fidelity numerical simulation of the flow field around a NACA-0012 aerofoil from the laminar separation bubble to a full stall." International Journal of Computational Fluid Dynamics 31, no. 4-5 (2017): 230245. https://doi.org/10.1080/10618562.2017.1330953

[4] Miozzi, Massimo, Alessandro Capone, Marco Costantini, Lorenzo Fratto, Christian Klein, and Fabio Di Felice. "Skin friction and coherent structures within a laminar separation bubble." Experiments in Fluids 60, no. 1 (2019): 1-25. https://doi.org/10.1007/s00348-018-2651-8

[5] Carmichael, B. H. Low Reynolds number airfoil survey. National Aeronautics and Space Administration, Langley Research Center, 1981.

[6] Alam, Muhammad, and Neil D. Sandham. "Direct numerical simulation of 'short'laminar separation bubbles with turbulent reattachment." Journal of Fluid Mechanics $410 \quad$ (2000): 1-28. https://doi.org/10.1017/S0022112099008976

[7] Counsil, Joshua NN, and Kiari Goni Boulama. "Low-reynolds-number aerodynamic performances of the NACA 0012 and Selig-Donovan 7003 Airfoils." Journal of Aircraft 50, no. 1 (2013): 204-216. https://doi.org/10.2514/1.C031856

[8] Borgmann, David, Shirzad Hosseinverdi, Jesse C. Little, and Hermann F. Fasel. "Investigation of laminar separation bubbles using experiments, theory and DNS." In AIAA Aviation 2021 Forum, p. 2898.2021. https://doi.org/10.2514/6.2021-2898

[9] Malkiel, E., and R. E. Mayle. "Transition in a separation bubble." Journal of Turbomachinery 118, no. 4 (1996): $752-$ 759. https://doi.org/10.1115/1.2840931 
[10] Owen, P. R., and L. Klanfer. On the laminar boundary layer separation from the leading edge of a thin aerofoilv. Aeronautical Research Council London (United Kingdom), 1953.

[11] McGranahan, Bryan, and Michael Selig. "Surface oil flow measurements on several airfoils at low Reynolds numbers." In 21st AIAA Applied Aerodynamics Conference, p. 4067. 2003. https://doi.org/10.2514/6.2003-4067

[12] Uthra, M. P., and A. Daniel Antony. "Comparative Investigation of Laminar Separation Bubble on a Wing at Low Reynolds Number." International Journal of Vehicle Structures \& Systems 12, no. 3 (2020): $337-342$. https://doi.org/10.4273/ijvss.12.3.22

[13] Bernardos, Luis F., François Richez, and Vincent Gleize. "RANS modeling of laminar separation bubbles around airfoils at low Reynolds conditions." In AIAA Aviation 2019 Forum, p. 2922. 2019. https://doi.org/10.2514/6.2019$\underline{2922}$

[14] Goni Boulama, Kiari, and Joshua Counsil. "Validation of a low-cost transitional turbulence model for low-Reynoldsnumber external aerodynamics." In 20th AIAA Computational Fluid Dynamics Conference, p. 3698. 2011. https://doi.org/10.2514/6.2011-3698

[15] Gaster, M. "On the stability of parallel flows and the behaviour of separation bubbles." PhD diss., Queen Mary, University of London, 1963.

[16] Gaster, Michael. "Vortex shedding from slender cones at low Reynolds numbers." Journal of Fluid Mechanics 38, no. 3 (1969): 565-576. https://doi.org/10.1017/S0022112069000346

[17] Horton, H. P. "A Semi-empirical Theory for the Growth and Bursting of Laminar Separation Bubbles." ARC CP 1073 (1967).

[18] Ol, Michael, Brian McCauliffe, Ernest Hanff, Ulrich Scholz, and Christian Kähler. "Comparison of laminar separation bubble measurements on a low Reynolds number airfoil in three facilities." In 35th AIAA Fluid Dynamics Conference and Exhibit, p. 5149. 2005. https://doi.org/10.2514/6.2005-5149

[19] Selig, Michael, James Guglielmo, Andy Broern, and Philippe Giguere. "Experiments on airfoils at low Reynolds numbers." In 34th Aerospace Sciences Meeting and Exhibit, p. 62. 1996. https://doi.org/10.2514/6.1996-62

[20] Lissaman, P. B. S. "Low-Reynolds-number airfoils." Annual Review of Fluid Mechanics 15, no. 1 (1983): $223-239$. https://doi.org/10.1146/annurev.fl.15.010183.001255

[21] Fujii, Kozo. "Progress and future prospects of CFD in aerospace-Wind tunnel and beyond." Progress in Aerospace Sciences 41, no. 6 (2005): 455-470. https://doi.org/10.1016/i.paerosci.2005.09.001

[22] Derksen, R. W., M. Agelinchaab, and M. Tachie. "Characteristics of the Flow over a NACA0012 Airfoil at Low Reynolds Numbers." WIT Transactions on Engineering Sciences $59 \quad$ (2008): 143-152. https://doi.org/10.2495/AFM080141

[23] Yarusevych, Serhiy, John G. Kawall, and Pierre E. Sullivan. "Unsteady separated flow characterization on airfoils using time-resolved surface pressure measurements." AIAA Journal 46, no. 2 (2008): 508-516. https://doi.org/10.2514/1.33306

[24] Wang, Shengyi, Derek B. Ingham, Lin Ma, Mohamed Pourkashanian, and Zhi Tao. "Numerical investigations on dynamic stall of low Reynolds number flow around oscillating airfoils." Computers \& Fluids 39, no. 9 (2010): 15291541. https://doi.org/10.1016/j.compfluid.2010.05.004

[25] Alam, Mohammad, Keith Walters, and David Thompson. "Simulations of separated flow around an airfoil with ice shape using hybrid RANS/LES models." In 29th AIAA Applied Aerodynamics Conference, p. 3972.2011. https://doi.org/10.2514/6.2011-3972

[26] Lee, Bumseok, and James D. Baeder. "Prediction and validation of laminar-turbulent transition using SA- $\gamma$ transition model." In AIAA Scitech 2021 Forum, p. 1532. 2021. https://doi.org/10.2514/6.2021-1532

[27] Rumsey, Christopher L., and David Greenblatt. "Flow Control Predictions Using Unsteady Reynolds-Averaged Navier-Stokes Modeling: A Parametric Study." AIAA Journal 47, no. 9 (2009): 2259-2262. https://doi.org/10.2514/1.41855

[28] Counsil, J. N. N., and K. Goni Boulama. "Validating the URANS shear stress transport $\mathrm{\gamma}$ - Re $\theta$ model for low-Reynoldsnumber external aerodynamics." International Journal for Numerical Methods in Fluids 69, no. 8 (2012): 1411-1432. https://doi.org/10.1002/fld.2651

[29] Zheng, Xiaoqing, Chaoqun Liu, Feng Liu, and Cheng-I. Yang. "Turbulent transition simulation using the k- $\omega$ model." International Journal for Numerical Methods in Engineering 42, no. 5 (1998): 907-926. https://doi.org/10.1002/(SICI)1097-0207(19980715)42:5<907::AID-NME393>3.0.CO;2-T

[30] Suluksna, Keerati, and Ekachai Juntasaro. "Assessment of intermittency transport equations for modeling transition in boundary layers subjected to freestream turbulence." International Journal of Heat and Fluid Flow 29, no. 1 (2008): 48-61. https://doi.org/10.1016/j.ijheatfluidflow.2007.08.003

[31] Galbraith, Marshall, and Miguel Visbal. "Implicit large eddy simulation of low-Reynolds-number transitional flow past the SD7003 airfoil." In 40th Fluid Dynamics Conference and Exhibit, p. 4737.2010. https://doi.org/10.2514/6.2010-4737 
[32] Chen, Lili, Zheng Guo, Xiaolong Deng, and Zhongxi Hou. "Aerodynamic performance and transition prediction of low-speed fixed-wing unmanned aerial vehicles in full configuration based on improved $\gamma-\operatorname{Re} \theta$ model." Aerospace Science and Technology 107 (2020): 106281. https://doi.org/10.1016/j.ast.2020.106281

[33] Lodefier, Koen, Bart Merci, Chris De Langhe, and Erik Dick. "Transition modelling with the SST turbulence model and an intermittency transport equation." In Turbo Expo: Power for Land, Sea, and Air, vol. 36886, pp. $771-777$. 2003. https://doi.org/10.1115/GT2003-38282

[34] Langtry, Robin B., and Florian R. Menter. "Correlation-based transition modeling for unstructured parallelized computational fluid dynamics codes." AIAA Journal 47, no. 12 (2009): 2894-2906. https://doi.org/10.2514/1.42362

[35] Menter, Florian R. "Two-equation eddy-viscosity turbulence models for engineering applications." AIAA Journal 32, no. 8 (1994): 1598-1605. https://doi.org/10.2514/3.12149

[36] Baltazar, João, Douwe Rijpkema, and José Falcão de Campos. "On the use of the $\mathrm{\gamma}-\mathrm{R}^{\sim}$ e $\theta t$ transition model for the prediction of the propeller performance at model-scale." Ocean Engineering 170 (2018): 6-19. https://doi.org/10.1016/i.oceaneng.2018.10.005

[37] Sreejith, B. K., A. Sathyabhama, and S. Sandeep Kumar. "Comparative study on the aerodynamic performance of airfoil with boundary layer trip of various geometrical shapes." In Journal of Physics: Conference Series, vol. 1854, no. 1, p. 012003. IOP Publishing, 2021. https://doi.org/10.1088/1742-6596/1854/1/012003

[38] Wauters, Jolan, Joris Degroote, and Jan Vierendeels. "Comparative study of transition models for high-angle-ofattack behavior." AIAA Journal 57, no. 6 (2019): 2356-2371. https://doi.org/10.2514/1.J057249

[39] Rogowski, Krzysztof, Grzegorz Królak, and Galih Bangga. "Numerical Study on the Aerodynamic Characteristics of the NACA 0018 Airfoil at Low Reynolds Number for Darrieus Wind Turbines Using the Transition SST Model." Processes 9, no. 3 (2021): 477. https://doi.org/10.3390/pr9030477

[40] Andan, Amelda Dianne, and Duck-Joo Lee. "Discrete Tonal Noise of NACA0015 Airfoil at Low Reynolds Number." Journal of Advanced Research in Fluid Mechanics and Thermal Sciences 53, no. 1 (2019): 129-145.

[41] Langtry, Robin B., and Florian R. Menter. "Correlation-based transition modeling for unstructured parallelized computational fluid dynamics codes." AIAA Journal 47, no. 12 (2009): 2894-2906. https://doi.org/10.2514/1.42362

[42] ANSYS. ANSYS Fluent Theory Guide. Release 15.0. ANSYS Inc., 2013.

[43] Miley, Stan J. Catalog of low-Reynolds-number airfoil data for wind-turbine applications. No. RFP-3387. Rockwell International Corp., Golden, CO (USA). Rocky Flats Plant; Texas A and M Univ., College Station (USA). Dept. of Aerospace Engineering, 1982. https://doi.org/10.2172/5044823

[44] Jacobs, Eastman N., and Albert Sherman. "Airfoil section characteristics as affected by variations of the Reynolds number." NACA Technical Report 586 (1937): 227-267.

[45] Rezaeiha, Abdolrahim, Hamid Montazeri, and Bert Blocken. "On the accuracy of turbulence models for CFD simulations of vertical axis wind turbines." Energy $180 \quad$ (2019): $838-857$. https://doi.org/10.1016/j.energy.2019.05.053

[46] Park, Donghun, Hojoon Shim, and Yunggyo Lee. "PIV measurement of separation bubble on an airfoil at low Reynolds numbers." Journal of Aerospace Engineering 33, no. 1 (2020): 04019105. https://doi.org/10.1061/(ASCE)AS.1943-5525.0001099

[47] Tangermann, Eike, and Markus Klein. "Numerical simulation of laminar separation on a NACA0018 airfoil in freestream turbulence." In AIAA Scitech 2020 Forum, p. 2064. 2020. https://doi.org/10.2514/6.2020-2064

[48] Grille Guerra, Adrian, Shirzad Hosseinverdi, Ashish Singh, Jesse C. Little, and Hermann F. Fasel. "Unsteady evolution of a laminar separation bubble subjected to structural motion." In AlAA Aviation 2021 Forum, p. 2949.2021. https://doi.org/10.2514/6.2021-2949 